\title{
MICROBIAL DEGRADATION OF ENDOSULFAN IN AGRICULTURAL SOILS
}

\author{
B.S. Ismail ${ }^{*}$ and A.O.S. Enoma \\ School of Environmental and Natural Resource Sciences, Faculty of Science \\ and Technology, Universiti Kebangsaan Malaysia, 43600 Bangi, Selangor, \\ Malaysia
}

\section{U.B. Cheah, K.Y. Lum, and Zulkifli Malik}

Centre for Strategic, Environment and Natural Resources Research, Malaysian Agricultural Research and Development Institute (MARDI), P.O. Box 12301, 50774 Kuala Lumpur, Malaysia

Received 26 July 2005,

\begin{abstract}
A study of the degradation of endosulfan $(6,7,8,9,10,10$-hexachloro - 1, 5, 5a, 6, 9, 9a hexahydro - 6, 9- methano - 2, 4, 3 - benzodioxanthiepin 3 - oxide) in Malaysian sandy loam and clay soils was carried out using a radioisotopic technique under laboratory conditions. It was demonstrated that endosulfan possessed long half-lives of 433, 495 and 462 days in aerobic sandy loam, aerobic clay and anaerobic clay soils respectively. Endosulfan degrades faster in non-sterile than in sterile soils. This study indicates that microorganisms are involved in the degradation of endosulfan. In general, degradation of the pesticide was relatively higher in the clay soil than in the sandy soil. Apart from the parent compounds, $\alpha$ - and $\beta$-isomers, the degradation products include endosulfan sulphate and three minor unidentified products.
\end{abstract}

Keywords: Endosulfan; Degradation; Half-life; Soil

\section{INTRODUCTION}

Most of the pesticides applied reach the soil by preemergence spraying with herbicides, by seed $\mathrm{d} 8$ ressing and spraying with fungicides and insecticides, by soil fumigation with nematicides, by wash-off, and by working with treated plants. Endosulfan, an agricultural insecticide has been demonstrated to be toxic to estuarine fauna (Pennington et al., 2004; and amphibian populations (Christin et al., 2004). The pesticides are subjected to degradation processes in soil which, depending on the physico-chemical behavior of the active ingredient and the prevailing soil and climatic conditions, lead to different mineralization and fixation rates in the soil. The degradation process determines the persistence of a pesticide in the soil environment and consequently its performance and also its impacts on the environment. Pennington et al. (2004) reported that endosulfan rapidly disappeared in the sediment and water by $96 \mathrm{hr}$.

The persistence of endosulfan $(6,7,8,9,10,10$-hexachloro-1,5,5a,6,9,9a-hexahydro-6,9methano-2,4,3-benzodioxanthiepin3-oxide) in soils has been studied by several researchers

${ }^{*}$ Corresponding author e-mail: ismail@pkrisc.cc.ukm.my 
(Steward and Cairns, 1974; Miles and Moy, 1975; Rao and Murty 1980; Beach et al. 1995; Kathpal et al. 1997). These authors reported different half-lives of endosulfan ranging from 1.1 weeks (2) to 26.67 months (Steward and Cairns 1974; Ghadiri and Rose 2001) though most results point to long half-lives of the insecticide in soils. Endosulfan sulphate has been identified as the main metabolite in soils but the persistence of the compound varied in different soils. Other degradation products include endosulfan diol, endosulfan ether and endosulfan lactone. Many of the studies on degradation of endosulfan were carried out in temperate regions but very limited reports are available on the persistence of endosulfan in tropical regions such as Malaysia.

The objectives of this study were to evaluate the rate and products of degradation of endosulfan in the sandy loam and clay soils taken from two agricultural areas, Cameron Highlands and MADA, Kedah, Malaysia.

\section{MATERIALS AND METHODS}

\section{Experimental set-up}

Two soil types, namely sandy loam (containing $69 \%$ sand, $23 \%$ silt and $8 \%$ clay with $1.9 \%$ organic matter) and clay soils (containing $12 \%$ sand, $33 \%$ silt and $55 \%$ clay with $1.64 \%$ organic matter) were collected respectively from the site of field plots in the Cameron Highlands and a paddy-growing area in Kedah, Malaysia. The soils were air-dried and passed through a 2-mm sieve and used immediately.

Each $100 \mathrm{~g}$ (weight on air-dried) soil sample was deposited in a biometer flask, which consists of a $250 \mathrm{ml}$ Erlenmeyer flask with a side arm. The side arm contained $10 \mathrm{ml}$ of $0.1 \mathrm{~N} \mathrm{NaOH}$ to absorb $\left.{ }^{14} \mathrm{C}_{\left[\mathrm{CO}_{2}\right]}\right]$ liberated due to microbial degradation, and the flask was covered with a rubber stopper. The soil was kept at a water-holding capacity of $50 \%$ for the duration of the study. Maintaining the soil at this moisture content was accomplished through occasional weighing of the flasks and any loss in weight corrected by adding an accurate amount of sterilized water. The experiment was conducted in a cabinet chamber at a temperature of $30^{\circ} \mathrm{C}\left( \pm 2^{\circ} \mathrm{C}\right), 80 \%( \pm$ $1 \%$ ) humidity and in complete darkness to avoid photodegradation. Autoclaved soil (sterilized at $15 \mathrm{kPa}$ for $15 \mathrm{~min}$ at a temperature of $121^{\circ} \mathrm{C}$ ) was used as control.

\section{Treatments}

Radiolabelled endosulfan $(18.5 \mathrm{kBq})$, supplemented with non-labelled analytical standard materials of the pesticide, was added to the biometer flasks containing the moist soils. The dose was based on the field application rate recommended for use in Malaysia, $0.25-0.3 \mathrm{~kg} \mathrm{ha}^{-1}$.

In calculating the dose of the pesticides needed for the study, it was assumed that pesticide leaching in soil does not take place at a depth greater than $10 \mathrm{~cm}$. The amounts of analytical grade endosulfan added to ${ }^{14} \mathrm{C}$-labelled pesticide was $20 \mu \mathrm{g}$ based on the highest recommended application rate. Treatments for the clay soil were administered under aerobic and anaerobic situations to mimic flooded and non-flooded conditions (approx. 50\% water holding capacity) typical of a paddy field. The flooded soil was left to equilibrate overnight before pesticide was applied. The sandy loam soil was treated only under non-flooded conditions, in harmony with the prevailing agricultural practice in the Cameron Highlands. Treatments were carried out in triplicate. 


\section{Recovery study on the analytical procedure}

The suitability of the extraction method for endosulfan was assessed using sandy loam and clay soils. The process involved spiking $100 \mathrm{~g}$ of each soil with $0.05 \mu \mathrm{Ci}$ of ${ }^{14} \mathrm{C}$-labeled materials of endosulfan into the soil extraction was carried out. The amount of analytical grade endosulfan added to ${ }^{14} \mathrm{C}$-labeled endosulfan was $20 \mu \mathrm{g}$ based on the highest recommendation application rate.

\section{Assay for total soil microorganism population}

The soils taken from biometer flasks identical to those used in the degradation studies were evaluated for their total bacterial counts so as to ascertain the effect of the closed system of the flask on the microbial population of the soils. Ten $g$ soil were sampled at $0,1,14,30$ and 60 days after treatment (DAT). Twenty three $g$ of nutrient agar consisting of Bacto beef extract (3 $\mathrm{g})$, Bacto peptone $(5 \mathrm{~g})$ and Bacto agar $(15 \mathrm{~g})$ added to $800 \mathrm{ml}$ of sterilized water, was heated on a hot plate magnetic stirrer until uniform solubility was achieved. The final solution was then made up to 1 litre with sterilized water. The agar was sterilized at $15 \mathrm{kPa}$ for $15 \mathrm{~min}$ at a temperature of $121^{\circ} \mathrm{C}$, then left to cool at room temperature prior to pouring into dishes. Agar plating was carried out at the rate of $25 \mathrm{ml}$ per plate and left to solidify overnight. A soil sample $(10 \mathrm{~g})$ collected at specified intervals of time was added to a conical flask containing $90 \mathrm{ml}$ of sterilized water, then shaken on a rotary shaker for $1 \mathrm{hr}$. This was followed by serial dilution of 10- fold steps and the appropriate dilutions plated out onto nutrient agar plates and incubated for a duration of $24-48 \mathrm{hr}$ at $30^{\circ} \mathrm{C}$ before counting was carried out. Results of microbial counting are expressed in colony forming units (CFU).

\section{Sampling/extraction}

Sampling was carried out at 1, 3, 7, 10, 14, 21, 30, 45 and 60 DAT. At each time interval, three replicate biometer flasks were sampled. The $\mathrm{NaOH}$ solution in the flask was sampled at each of the specified intervals. An aliquot $(2 \mathrm{ml})$ of $\mathrm{NaOH}$ was radioassayed. The amounts of ${ }^{14} \mathrm{CO}_{2}$ released at each sampling time were calculated as a percentage of the total radioactivity applied to the soils. At each specified interval, soil samples were subjected to solvent-extraction and examination by thin layer chromatography (TLC). An aliquot of soil extract (100 $\mu \mathrm{L})$ was radioassayed. After solvent extraction, the soil was air-dried and an aliquot $(0.3 \mathrm{~g})$ was oxidized to determine nonextractable residues. Half-life was determined by plotting the logarithm of concentration against time, by which a straight-line graph was obtained with the slope proportional to the rate constant.

\section{Extraction and thin-layer chromatography of endosulfan}

Soil weighing $100 \mathrm{~g}$ was deposited in a glass-stoppered flask and extracted with a solvent mixture of chloroform and diethyl ether $(100 \mathrm{~mL} ; 1: 1 \mathrm{v} / \mathrm{v})$. The flask was shaken on an orbital shaker at $150 \mathrm{rpm}$ for $4 \mathrm{hr}$. The contents were filtered and an aliquot of the filtrate $(100 \mu \mathrm{L})$ was radioassayed. The extract concentrates were brought to a final volume of $2 \mathrm{~mL}$ using a rotary evaporator. An aliquot of the soil extract $(30 \mu \mathrm{L})$ was examined on a $20 \times 20 \mathrm{~cm}$ Merck TLC plate pre-coated with silica gel $\mathrm{F}_{254}$ to a layer thickness of $1 \mathrm{~mm}$. The plate was developed by employing a mixture of hexane and acetone $(9: 1 \mathrm{v} / \mathrm{v})$ and allowed to air-dry at room temperature for $6 \mathrm{hr}$. It was viewed under a UV Chromato-Vue cabinet (UVP model CC-60) and then subjected to further development with an X-ray film. Nonradioactive standards of endosulfan I, endosulfan II and endosulfan sulfate with $\mathrm{R}_{\mathrm{f}}$ values of $0.9 \mathrm{~cm}, 0.55 \mathrm{~cm}$ and $0.4 \mathrm{~cm}$, respectively were run for comparative purposes. 


\section{Statistical analysis}

SAS software was used in statistical analyses of half-life of the pesticide as determined from laboratory studies.

\section{RESULTS AND DISCUSSION}

\section{Recovery study on analytical procedure}

Recoveries of $80.0 \%$ and $84.28 \%$ were obtained for endosulfan in the clay and sandy loam soils, respectively. Although the percentage recovery obtained for endosulfan in the clay soil was relatively low, low standard deviation demonstrates its consistency and reproducibility. The outcome of the recovery studies carried out on endosulfan showed that the extraction methods used in this study for the pesticides were acceptable.

\section{Assay for Total Microbial Population}

There was no significant difference in the microbial population of the sandy loam soil on the day the studies commenced and after 60 days (Table 1). A similar trend was observed for the clay soil. There was a slight increase of microbial mass at 60 DAT in both soils. These observations indicate that the closed system under which the degradation studies were conducted had no adverse effect on the microbial population.

Table 1: Total bacterial counts in the sandy loam and clay soils

\begin{tabular}{ccc}
\hline & \multicolumn{2}{c}{ Bacterial Counts $\left(\mathbf{C F U} / \mathbf{g}\right.$ Soil $\left.\times \mathbf{1 0}^{\mathbf{6}}\right)$} \\
\cline { 2 - 3 } Incubation Time (days) & Sandy Loam & Clay \\
\hline 0 & $2.09( \pm 0.25)$ & $4.2( \pm 1.71)$ \\
1 & $6.92( \pm 1.7)$ & $4.8( \pm 0.04)$ \\
14 & $8.81( \pm 0.01)$ & $6.1( \pm 0.07)$ \\
30 & $9.2( \pm 1.33)$ & $7.8( \pm 0.00)$ \\
60 & $8.34( \pm 0.00)$ & $9.4( \pm 0.03)$ \\
\hline
\end{tabular}

Standard deviation, $( \pm)$.

\section{Microbial Degradation of Endosulfan}

The recovered radioactivity ranged from $84.66 \%$ to $101.24 \%$ for the aerobic sandy loam soil, from $74.39 \%$ to $93.98 \%$ in the aerobic clay and from $80.27 \%$ to $98.52 \%$ in the anaerobic clay. The degradation of endosulfan in the autoclaved soil ranged from $0.11 \%$ to $0.42 \%$ in the aerobic sandy loam soil, from $0.09 \%$ to $0.30 \%$ in the aerobic clay and from $0.05 \%$ to $0.26 \%$ in the anaerobic clay. In the non-autoclaved soil, degradation rates range from $0.39 \%$ to $8.8 \%$ in the aerobic sandy loam, from $1.03 \%$ to $10.5 \%$ in the aerobic clay and from $1.21 \%$ to 12.20 $\%$ in the anaerobic clay (Tables 2 and 3). The significant differences in the rate of degradation of ${ }^{14} \mathrm{C}$ [endosulfan] between autoclaved and non-autoclaved soils demonstrate the involvement of microbial action in the degradation of endosulfan in the studied soils. Many pesticide 
compounds are mainly degraded by soil microbes (Walker 1978; Ismail et al. 1998) as well as by other chemical processes such as hydrolysis (Hammamda et al. 1994).

It was observed that the degradation of the pesticide increased with increasing sampling intervals. The microbial degradation of endosulfan $(8.8 \%, 10.5 \%$ and $12.2 \%$ at 60 DAT in the aerobic sandy loam, aerobic clay and anaerobic clay, respectively) was generally slow and reflected the pesticide's persistence in the environment. Other reports have shown that for $\gamma$ BHC (also from the organochlorine group), a more rapid degradation occurred under flooded conditions than under nonflooded conditions (Yashida and Castro 1970). The degradation of the pesticide was relatively higher in the clay soil than in the sandy loam, irrespective of whether the soils were autoclaved or non-autoclaved (Tables 2 and 3).

Table 2: $\quad$ The rate of degradation of endosulfan in sandy loam soil as measured by the evolution of ${ }^{14} \mathrm{CO}_{2}$

\begin{tabular}{ccc}
\hline & \multicolumn{2}{c}{ Degradation (\% Applied) } \\
${ }^{\mathrm{a}} \mathbf{D A T}$ & ${ }^{\mathbf{b}} \mathbf{S S}$ & ${ }^{\mathbf{c}} \mathbf{N S}$ \\
\hline 1 & $0.11( \pm 0.01)$ & $0.39( \pm 0.03)$ \\
3 & $0.13( \pm 0.00$ & $0.56( \pm 0.64)$ \\
7 & $0.17( \pm 0.03)$ & $0.74( \pm 0.10)$ \\
10 & $0.18( \pm 1.10)$ & $1.67( \pm 0.23)$ \\
14 & $0.21( \pm 0.01)$ & $1.85( \pm 0.01)$ \\
21 & $0.23( \pm 0.04)$ & $3.18( \pm 0.00)$ \\
30 & $0.25( \pm 0.03)$ & $5.22( \pm 0.01)$ \\
45 & $0.35( \pm 0.01)$ & $7.10( \pm 0.02)$ \\
60 & $0.42( \pm 0.01)$ & $8.8( \pm 0.22)$ \\
\hline
\end{tabular}

${ }^{a}$ DAT (Days after treatment), ${ }^{b} \mathrm{SS}$ (Sterilized soil), ${ }^{\mathrm{c}} \mathrm{NS}$ (Non-sterilized soil).

Table 3: $\quad$ The rate of degradation of endosulfan in aerobic and anaerobic clay soil as measured by the evolution of ${ }^{14} \mathrm{CO}_{2}$

\begin{tabular}{|c|c|c|c|c|}
\hline \multirow[b]{3}{*}{${ }^{\mathbf{a}} \mathbf{D A T}$} & \multicolumn{4}{|c|}{ Degradation (\% Applied) } \\
\hline & \multicolumn{2}{|c|}{ Endosulfan (Aerobic Clay) } & \multicolumn{2}{|c|}{ Endosulfan (Anaerobic Clay) } \\
\hline & ${ }^{\mathbf{b}} \mathrm{SS}$ & ${ }^{\mathrm{c}} \mathrm{NS}$ & SS & NS \\
\hline 1 & $0.09( \pm 0.01)$ & $1.03( \pm 0.18)$ & $0.05( \pm 0.00)$ & $1.21( \pm 0.18)$ \\
\hline 3 & $0.10( \pm 0.00)$ & $1.05( \pm 0.06)$ & $0.07( \pm 0.01)$ & $1.29( \pm 0.06)$ \\
\hline 7 & $0.14( \pm 0.05)$ & $1.10( \pm 0.01)$ & $0.09( \pm 0.00)$ & $1.38( \pm 0.01)$ \\
\hline 10 & $0.17( \pm 0.01)$ & $1.23( \pm 0.00)$ & $0.1( \pm 0.00)$ & $1.57( \pm 0.00)$ \\
\hline 14 & $0.20( \pm 0.00)$ & $1.58( \pm 0.00)$ & $0.15( \pm 0.01)$ & $1.64( \pm 0.00)$ \\
\hline 21 & $0.26( \pm 0.01)$ & $1.92( \pm 0.01)$ & $0.18( \pm 0.00)$ & $2.01( \pm 0.01)$ \\
\hline 30 & $0.28( \pm 0.00)$ & $2.31( \pm 0.02)$ & $0.19( \pm 0.01)$ & $2.43( \pm 0.02)$ \\
\hline 45 & $0.29( \pm 0.01)$ & $3.4( \pm 0.02)$ & $0.21( \pm 0.00)$ & $2.65( \pm 0.02)$ \\
\hline 60 & $0.30( \pm 0.02)$ & $10.5( \pm 0.5)$ & $0.26( \pm 0.00)$ & $12.2( \pm 0.5)$ \\
\hline
\end{tabular}

${ }^{a}$ DAT (Days after treatment), ${ }^{b} \mathrm{SS}$ (Sterilized soil), ${ }^{\mathrm{C}} \mathrm{NS}$ (Non-sterilized soil). 
A plot of the logarithmic values of soil concentrations versus time showed a linear relationship for the aerobic sandy loam $\left(r^{2}=0.99\right)$, aerobic clay loam $\left(r^{2}=0.75\right)$ and anaerobic clay loam $\left(r^{2}=0.65\right)$. Half-lives of $433.25,495.14$ and 462.13 days were estimated from the first-order kinetics of the degradation process for the respective soils (Table 4).

Table 4: First-order rate constants $(K)$, half-lives $\left(T_{1 / 2}\right)$ and correlation coefficients of endosulfan in the sandy loam and clay soils

\begin{tabular}{lccc}
\hline Soil Condition & $\mathbf{r}^{\mathbf{2}}$ & $\mathbf{K}\left(\right.$ Days $\left.^{-\mathbf{1}}\right)$ & $\mathbf{t}_{\mathbf{1} / \mathbf{2}}$ (Days) \\
\hline Aerobic Sandy Loam & 0.99 & 0.0016 & 433.25 \\
Aerobic Clay & 0.75 & 0.0014 & 495.14 \\
Anaerobic Clay & 0.65 & 0.0015 & 462.13 \\
\hline
\end{tabular}

Several metabolites were formed at different stages of the degradation of endosulfan, including endosulfan sulphate and three unidentified compounds (designated as unidentified compound 1, unidentified compound 2 and unidentified compound 3). It was observed that the number and relative abundance of the metabolites differed with soil types and across flooded or non-flooded conditions (Tables 5, 6 and 7). Table 5 shows the percentage of the degradation products of endosulfan in aerobic sandy loam soil. Three metabolites were observed in the aerobic sandy loam soil comprising endosulfan sulphate (3.17\%), unidentified compound $1(0.8 \%)$ and unidentified compound $2(1.26 \%)$.

Table 5: Degradation products of endosulfan in aerobic sandy loam soil

\begin{tabular}{|c|c|c|c|c|c|c|c|}
\hline Compound & $\mathbf{R}_{\mathbf{f}}$ & ${ }^{\mathrm{a}} 7$ & 14 & 21 & 45 & 60 & Mean (\%) \\
\hline $\begin{array}{l}\text { Alpha } \\
\text { Endosulfan }\end{array}$ & 0.9 & ${ }^{\mathrm{b}} 17.4 \pm 1.0$ & $58.2 \pm 13.2$ & $45.8 \pm 4.3$ & $35.6 \pm 1.6$ & $48.4 \pm 3.0$ & 41.1 \\
\hline $\begin{array}{l}\text { Beta } \\
\text { Endosulfan }\end{array}$ & 0.6 & $78.8 \pm 1.3$ & $31.5 \pm 8.9$ & $49.3+3.0$ & $60.7 \pm 4.0$ & $48.2 \pm 3.3$ & 53.7 \\
\hline $\begin{array}{l}\text { Endosulfan } \\
\text { Sulphate }\end{array}$ & 0.4 & $2.7 \pm 0.14$ & $8.4 \pm 3.2$ & $2.0 \pm 1.1$ & $1.8 \pm 0.2$ & $1.0 \pm 0.1$ & 3.2 \\
\hline $\begin{array}{l}\text { Unidentified } \\
\text { Compound } 1\end{array}$ & 0.3 & $1.0 \pm 0.1$ & $1.5 \pm 1.2$ & $0.8 \pm 0.1$ & $0.3 \pm 0.1$ & $0.4 \pm 0$ & 0.8 \\
\hline $\begin{array}{l}\text { Unidentified } \\
\text { Compound } 2\end{array}$ & 0.2 & $0.2 \pm 0.1$ & $0.5 \pm 0.2$ & $2.1 \pm 1.8$ & $1.6 \pm 0.5$ & $2.0 \pm 0.2$ & 1.3 \\
\hline $\begin{array}{l}\text { Unidentified } \\
\text { Compound } 3\end{array}$ & 0.7 & - & - & - & - & - & - \\
\hline
\end{tabular}

${ }^{a}$ Days after treatment, ${ }^{b}$ percentage abundance of metabolite.

Table 6 shows the degradation products of endosulfan in aerobic clay soil. In aerobic clay soil, four metabolites were detected, including endosulfan sulphate $(7.57 \%)$, unidentified compound 1 (6.91\%), unidentified compound $2(3.91 \%)$ and unidentified compound $3(13.88 \%)$. The 
submerged clay soil also had these four metabolites but in differing proportions from the nonflooded soil (Table 7); endosulfan sulphate (20.50\%), unidentified compound 1 (11.51\%), unidentified compound $2(30.24 \%)$ and unidentified compound $3(13.20 \%)$. It was observed in the current study that the amount of endosulfan sulphate in the flooded clay soil $(20.50 \%)$ was proportionally more than in the non-flooded clay soil $(7.57 \%)$. Cheah et al. (1998) reported that the highest concentration of endosulfan sulfate, $\beta$-endosulfan and $\alpha$-endosulfan isomers in soils collected from Cameron Highlands during 1991 - 1992 were $0.43,0.46$ and $0.2 \mathrm{mg} \mathrm{kg}^{-1}$ soil, respectively. This study confirms that endosulfan sulfate is one of the important degradation products of endosulfan in soil.

Table 6: Degradation products of endosulfan in aerobic clay soil

\begin{tabular}{lccccccc}
\hline Compound & $\mathbf{R}_{\mathbf{f}}$ & ${ }^{\mathrm{a}} \mathbf{7}$ & $\mathbf{1 4}$ & $\mathbf{2 1}$ & $\mathbf{4 5}$ & $\mathbf{6 0}$ & Mean (\%) \\
\hline $\begin{array}{l}\text { Alpha } \\
\text { Endosulfan }\end{array}$ & 0.9 & ${ }^{\mathrm{b}} 76.7 \pm 8.1$ & $32.8 \pm 4.7$ & $38.8 \pm 0$ & $37.3 \pm 5.4$ & $33.9 \pm 0.5$ & 43.9 \\
$\begin{array}{l}\text { Beta } \\
\text { Endosulfan }\end{array}$ & 0.6 & $22.0 \pm 1.9$ & $34.2 \pm 2.1$ & $25.2 \pm 0.1$ & $25.4 \pm 2.6$ & $26.3 \pm 0.8$ & 26.6 \\
$\begin{array}{l}\text { Endosulfan } \\
\text { Sulphate }\end{array}$ & 0.4 & $0.6 \pm 0$ & $5.7 \pm 0$ & $10.4 \pm 0$ & $10.6 \pm 1.9$ & $10.9 \pm 1.6$ & 7.6 \\
$\begin{array}{l}\text { Unidentified } \\
\text { Compound 1 }\end{array}$ & 0.3 & $0.2 \pm 0.1$ & $7.7 \pm 0.1$ & $7.0 \pm 0.3$ & $9.3 \pm 0.3$ & $10.3 \pm 2.4$ & 6.9 \\
$\begin{array}{l}\text { Unidentified } \\
\text { Compound 2 }\end{array}$ & 0.2 & $0.4 \pm 0.2$ & $4.2 \pm 0$ & $4.0 \pm 1.0$ & $4.6 \pm 0.3$ & $6.4 \pm 0.4$ & 3.9 \\
$\begin{array}{l}\text { Unidentified } \\
\text { Compound 3 }\end{array}$ & 0.7 & - & $15.9 \pm 3.5$ & $14.6 \pm 2.6$ & $12.8 \pm 4.7$ & $12.2 \pm 3.1$ & 13.9 \\
\hline
\end{tabular}

${ }^{\mathrm{a}}$ Days after treatment, ${ }^{\mathrm{b}}$ percentage abundance of metabolite.

Table 7: Degradation products of endosulfan in anaerobic clay soil

\begin{tabular}{lccccccc}
\hline Compound & $\mathbf{R}_{\mathbf{f}}$ & $\mathbf{7}^{\mathrm{a}}$ & $\mathbf{1 4}$ & $\mathbf{2 1}$ & $\mathbf{4 5}$ & $\mathbf{6 0}$ & Mean (\%) \\
\hline $\begin{array}{l}\text { Alpha } \\
\text { Endosulfan }\end{array}$ & 0.9 & ${ }^{\mathrm{b}} 16.9 \pm 2.4$ & $19.3 \pm 1.1$ & $16.6 \pm 5.2$ & $25.7 \pm 4.3$ & $18.6 \pm 0.7$ & 19.4 \\
$\begin{array}{l}\text { Beta } \\
\text { Endosulfan }\end{array}$ & 0.6 & $5.1 \pm 0.2$ & $6.0 \pm 0.1$ & $4.4 \pm 0$ & $3.7 \pm 0.3$ & $6.7 \pm 1.3$ & 5.2 \\
$\begin{array}{l}\text { Endosulfan } \\
\text { Sulphate }\end{array}$ & 0.4 & $22.4 \pm 1.4$ & $21.4 \pm 0$ & $23.2 \pm 1.2$ & $21.6 \pm 0.5$ & $13.9 \pm 1.3$ & 20.5 \\
$\begin{array}{l}\text { Unidentified } \\
\text { Compound 1 }\end{array}$ & 0.3 & $11.8 \pm 0$ & $12.6 \pm 0$ & $12.1 \pm 0.7$ & $10.6 \pm 1.0$ & $10.5 \pm 1.1$ & 11.5 \\
$\begin{array}{l}\text { Unidentified } \\
\text { Compound 2 }\end{array}$ & 0.2 & $26.0 \pm 1.3$ & $23.7 \pm 0.7$ & $26.4 \pm 0.7$ & $27.2 \pm 1.9$ & $47.9 \pm 2.6$ & 30.2 \\
$\begin{array}{l}\text { Unidentified } \\
\text { Compound 3 }\end{array}$ & 0.7 & 17.8 & 17.1 & 17.3 & 11.3 & 2.4 & 13.2 \\
\hline
\end{tabular}

${ }^{a}$ Days after treatment, ${ }^{b}$ percentage abundance of metabolite 
Three findings emerge from this study. First, the faster degradation rate of endosulfan in nonautoclaved than in autoclaved soils clearly indicates that microbial degradation is one of the processes participating in the dissipation of endosulfan in the soil environment. Second, degradation products of endosulfan were found to include endosulfan sulfate and three unidentified compounds. Third, we found that soil texture also affected the half-life of endosulfan, which was found to be longer in clay than in sandy loam soil.

\section{ACKNOWLEDGEMENTS}

The work was supported by research grant IRPA 08-02-02-0011 EA185 from the Ministry of Science, Technology and Innovation of Malaysia.

\section{REFERENCES}

1. Beach, E.D., Fernandez-Cornejo, J. and Huang, W.Y. (1995), The potential risks of groundwater and surface water contamination by agricultural chemicals used in vegetable production. J. Environ. Sci. Health A3, pp. 1295-1325.

2. Cheah, U.B., Kirkwood, R.C. and Lum, K.Y. (1998), Degradation of four commonly used pesticides in Malaysian agricultural soils, J. Agric. Food Chem., vol. 46, pp. 12171223.

3. Christin M.S., Menard L., Gendron A.D., Ruby S., Cyr D., Marcogliese D.J., RollinsSmith L., and Fournier M. (2004), Effects of agricultural pesticides on the immune system of Xenopus laevis and Rana pipiens. Aquatic Toxicol, vol. 67, pp. 33-43.

4. Ghadiri H. and Rose C.W. (2001), Degredation of endosulfan in a clay soil from cotton farms of western Quensland, J. Environ. Manag, vol. 62, pp.155-169.

5. Hammamda, S., Calmon, M. and Calmon, J.P. (1994), Kinetics and hydrolysis mechanism of chlorsulfuron and metsulfuron-methyl, Pestic. Sci., vol. 40, pp. 71-76.

6. Ismail, B.S., Goh, K.M. and Kader, J. (1996), Effects of metsulfuron-methyl on microbial biomass and populations in soils, J. Environ. Sci. Health B31, pp. 987-999.

7. Kathpal, T.S., Singh, A., Dhankhar, J.S. and Singh, G. (1997), Fate of endosulfan in cotton soil under sub-tropical conditions of Northern India, Pestic. Sci., vol. 50, pp. 21-27.

8. Miles, J.R.W. and Moy, P. (1979), Degradation of endosulfan and its metabolites by a mixed culture of soil microorganisms, Bull. Environ. Contam. Toxicol, vol. 23, pp. 13-19.

9. Pennington, P.L., DeLorenzo, M.E., Lawton, J.C., Strozier, E.D., Fulton, M.H. and Scott, G.I. (2004), Modular estuarine mesocosm validation: ecotoxicological assessment of direct effects with the model compound endosulfan, J Experimental Marine Biol. and Ecol., vol. 298, pp. 369-387.

10. Rao, D.M.R. and Murty, A.S. (1980), Persistence of endosulfan in soils, J. Agric. Food Chem., vol. 28, pp. 1099-1101.

11. Steward, D.K.R. and Cairns, K.R. (1994), Endosulfan persistence in soil and uptake by potato tubers, J. Agric. Food Chem., vol. 22, pp. 984-986.

12. Walker, A. (1978), Simulation of persistence of eight soil applied herbicides, Weed Res., vol. 18, pp. 305-313.

13. Yoshida, T. and Castro, T.F. (1970), Degradation of gamma-BHC in rice soils, Soil Sci. Soc. Amer. Proc., vol. 34, pp. 440-442. 